\title{
Nutritional statusand associated factorsinelderly hospitalized incardiac
}

\section{care unit}

\author{
Payvar B*1 ${ }^{*}$, Abbaszade $\mathrm{A}^{2}$, Esteki $\mathrm{T}^{3}$, Talebighane $\mathrm{E}^{4}$, Safavibayat $\mathrm{Z}^{5}$
}

\begin{abstract}
Introduction and purpose: Nutrition is considered as an important health determinant among elderly. Malnutrition is recognized as a risk factor in several disease including cancer, heart disease, and dementia in older population. Therefore, this study aimed to assess nutritional status and associated factors among elderly hospitalized in cardiac care unit.
\end{abstract}

Materials and Methods: This descriptive-analytical study was conducted among 254 elderly patients (aged more than 60 years old) hospitalized in cardiac care unit due to cardiovascular disease. Data were collected using Mini nutritional assessment (MNA) questionnaires. SPSS version 20 was used to analyze data via appropriate descriptive and inferential statistical tests.

Findings: Findings from the current study showed that $16.9 \%$ suffered from malnutrition, $37.4 \%$ were at risk of malnutrition and $45.7 \%$ had satisfactory nutritional status. In addition, we found series of significant relationships between health status and nutrition as well as demographic factor ( $p$ value< 0/001).

Conclusion: Malnutrition is a common risk factor among hospitalized elderly which jeopardize their health status. Therefore, screening and recognizing hospitalized elderly who are at risk of malnutrition plays an important role in its prevention.

Keywords: Elderly, Nutritional Assessment, Mini Nutritional Assessment

Received: 2016/06/14 Accepted: 2016/09/5

Copyright () 2018 Quarterly Journal of Geriatric Nursing.This is an open-access article distributed under the terms of the Creative Commons Attribution international 4.0 International License(http://creativecommons.org/licenses/by /4.0/) which permits copy and redistribute the material, in any medium or format, provided the original work is properly cited.

1 - MSc in nursing critical care,Mashad university Medical Sciences, Quchan higher health education center,Mashhad,Iran (Corresponding Author):E-mail: baharpayvar@yahoo.com

2 - Professor, Faculty member, Shahid Beheshti University of Medical Sciences, Tehran,Iran

3 - Associate Professor, Faculty member, Shahid Beheshti University of Medical Sciences, Tehran,Iran

4 -Assisstant Professor, Faculty member, Shahid Beheshti University of Medical Sciences ,Tehran,Iran

5 - Ph.D student of Biostatistics, Shahid Beheshti University of Medical Sciences ,Tehran,Iran 


\section{بررسى وضعيت تغذيه و عوامل مرتبط با آن در سالمندان بسترى در بخشهاى مراقبت ويزه قلبى}

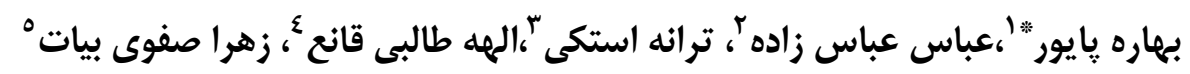

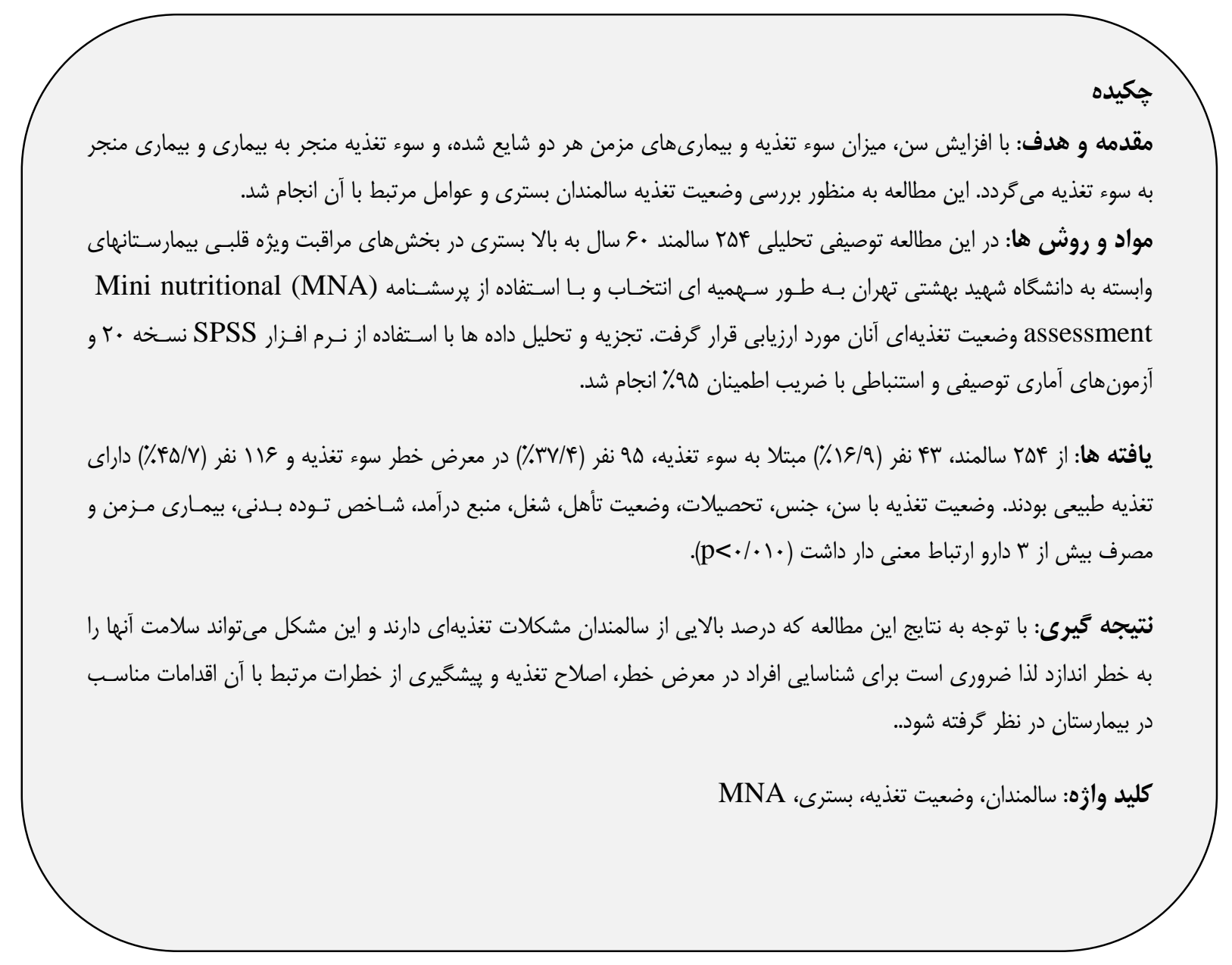

ا- كارشناس ارشد يرستارى مراقبت ويزه، دانشكاه علوم يزشكى مشهد، مجتمع آموزش عالى سلامت قوخان، مشهل، ايران (نويسنده مسؤول). يست الكترونيكيى: baharpayvar@yahoo.com

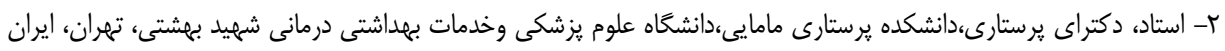

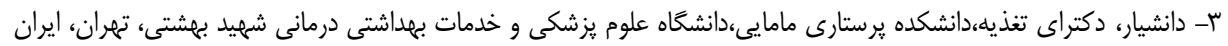

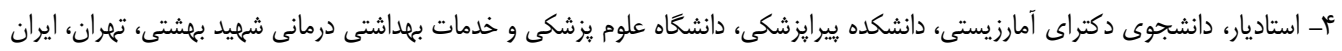

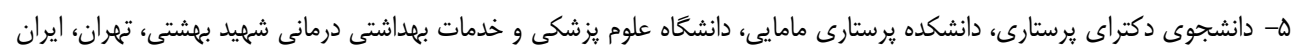


كاهش اشتها، كاهش مصرف ميان وعـدههــا در مـردان، تغييـر وضعيت سلامتى، مشكالات گوارشى، مصرف داروهـاى متعـدد، افسردگى و كاهش عملكرد شناختى است [^]. با توجه به اينكـهـ يرستاران در موقعيت بسيار خوبى بـراى شناسـايى علائسم فقـر تغذيه و اقدام براى تغيير هستند، تماس نزديكى بـا مـددجويان و خانواده آنها، يرسـتاران را قــادر بــه مشـاهده وضـعيت جسـمى، خوردن غذا، تغييرات وزن و پاسخ به درمان مىسازد. تشـخيص زودرس بيماران مبتلا به سوء تغذيه يـا در معـرض خطـر داراى اثرات مثبت بر نتايج سلامتى كوتاه مدت و بلند مـدت دارد، لـذا در اين يزوهش به بررسى وضعيت تغذيه و عوامل مرتبط بـا آن در سالمندان بسترى در بخشهاى مراقبت ويزه قلبى يرداختـه

\section{مواد و روشها}

ثروهش حاضر يك مطالعه توصيفى - تحليلى بوده كـه بـهـــور سهميهاى Fما نفر از سالمندان •ع سال و مسنتـر بسـترى در بخشهاى مراقبت ويزه قلبى بيمارستانهايمنتخـب وابسـته بـــ دانشخاه علوم يزشكى شـهيد بهشـتى (بيمارسـتانهـاى شـهيد مدرس، امام حسين، طرفه، لبافى نزاد و لقمان) را در شش ماهه اول سال سو انتخاب و مورد بررسـى قـرار داده اسـت. بيمـاران شركت كننده در اين مطالعه همكَى سن بالاى •ع سال داشـته، حداقل يكى روز در بخـش بسـترى بودنــد و از لحـاظ عقلى در سلامت كامل قرار داشتند.

ابزار كَردآورى دادهها

جهت جمع آورى اطلاعات از يرسشنامه ارزيابى مختصر تغذيهاى

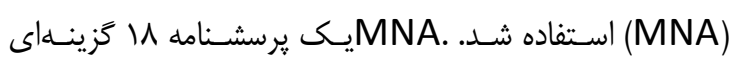
شامل اندازهيرىهاى تن سنجى (نمايه توده بــن(BMI)، دور
در قرن اخير، موفقيت در ارائه خدمات بهداشتى موجـب كـاهش ميزان بارورى در دنيا شده و نيز با توجه به بالا رفـتن اميـد بــه زندگى، جمعيت سالمندان نسبت به ساير گروههاى سنى افزايش جشمخيرى داشـته اسـت [1]. افـزايش جمعيـت سـالمندان بـهـ خصوص در كشورهاى در حال توسعه با افـزايش بيمـارىهـاى غير واگيردار مانند بيمارىهاى قلبى - عروقى، ديابت، آلزايمـر، سرطانها، بيمـارىهـاى مـزمن ريـهـ و مشـكلات عضـلانى -

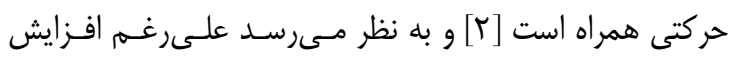
آكَاهى در بيشخَيرى از بيمارىهاى قلبى- عروقى و با توجه بــه مسن شدن جامعه، شيوع بيمارىهاى قلبى- عروقى افزايش ييدا كرده و در نتيجه نياز به تختهاى بخش مراقبـت ويـزه قلبـى' افزايش مىيابد [ب[]. با افزايش سن، ميزان سوء تغذيه و بيمارىهـاى مـزمن هــر دو شايع شده، و سوء تغذيه منجر به بيمارى و بيمارى منجر به سوء تغذيه مى ${ }^{2}$ [أ]. مطالعات نشان مى دهد كـه تغذيـه يكى از عوامل مهم تعيين كنــده سـلامت در سـالمندان بـوده و نقـش شناخته شدهاى در بيمارىهاى شايع سـالمندان مانـــــــرطان، بيمارىهاى قلبى - عروقى و دمانس دارد [ه]. كـاهش اشـتها، كاهش وزن و سوء تغذيه بطور عمده در ميان سالمندان بسـترى در بيمارستان ديده مىشود و همجنين بيمارىهاى حاد منجر به كاهش يروتئين و مواد مغذى ضرورى بدن شده كـه منجـر بــه وخيم شدن وضعيت سلامتى عمومى سالمندان خواهد شـد [ع]. در مطالعهاى مقطعى در يرتقال، بررسى عأfال بيمـار نشـان داد كه عس درصد از سالمندان در خطر سوء تغذيه و 9/V درصد آنان دجار سوء تغذيه بودند [V]]. علل سوء تغذيه در سالمندان بسترى ${ }^{1}$ Coronary Care Unit 
$\mathrm{BMI}=$ weight $(\mathrm{kg}) \div$ height $^{2}(\mathrm{~m})$

همجنين در •19 نفر از شركت كنندًان كه به دليل ناتوانى و يا دستور يزشك قادر به خروج از تخت نبودند محاسبه قــد و وزن به صورت غير مستقيم و با استفاده از فرمولهاى زير بهدست -

فرمول به دست آوردن وزن غير مستقيم [11]:

Weight $($ men $)=(0.98 \times$ calf circ. $)+(1.16$

$\times$ knee height $)+(1.73 \times$ MUAC $)+(0.37$

$\times$ sub scapular skinfold) - 81.69.

Weight $($ women $)=(1.27 \times$ calf circ. $)+$ $(0.87 \times$ knee height $)+(0.98 \times$ MUAC $)+$ $(0.4 \times$ sub scapular skinfold $)-62.35$.

$$
\text { فرمول به دست آوردن قد غير مستقيم [IT] }
$$

Height $($ men $)=(1.40 \times$ demi-span in $\mathrm{cm})$

Height $($ women $)=(1.35 \times$ demi-span in

$$
\mathrm{cm})+60.0
$$

و يس از جمع آورى يرسشنامهها و مقادير ذكر شـده، اطلاعـات جهت استخراج نتايج مورد تجزيه و تحليل قرار كرفت.

\section{روش تجزيه و تحليل داده ها}

براى تجزيه و تحليل دادههاى اين مطالعه ابتدا توصيف نتايج بـا استفاده از فراوانىها و درصدها انجام شد و در قسمت استنباطى براى متغيرهاى كيفى از آزمون كاى اسكور و آزمون دقيق فيشر و براى متغيرهاى كمـى در صـورت برقـرارى فـرض نرمـال از آزمــون آنـاليز واريـانس ودر صـورت نرمـال نبــودن از آزمـون كراسكال واليس استفاده شد. سطح اطمينان در تمام آزمـونهـا ه9/• درصد در نظر كرفته شد و تمامى تحليلها بـا استفاده از

$$
\text { نرم افزار SPSS نسخه ·r صورت كرفت. }
$$

1 -Mid upper arm circumference

بازو، دور ماهيجه ساق پا و وزن)، دريافت رزيمى (تعـداد وعـدههاى غذايى، دريافت غذا و مايعات و بىاشتهايى)، ارزيابى كلى (شـيوه زنــــى، داروهـا، تحــرى، وجـود اسـترس، دمـانس و افسردىى) و يك ارزيابى شخصى (نظر شخص در مورد سلامتى و تغذية) مىباشد [9]. يرسشنامهMNA در كلينيكهاى مختلف دنيـا بـه زبــانهـاى متعدد ترجمه و اعتبار سنجى شده است،در ايران نيز اين ابزار به زبان فارسى ترجمه و پِ از استاندارد سازى در جمعيت ايرانى مناسب تشخيص داده شده است [•|]. در اين مطالعه با استفاده از روش آزمون مجدد، بايائى برسشنامه را ارزيـابى نموديم كـهـ ضريب يايايى (ICC) در سه حيطه غربـالكرى، بررسى و نمـره كلى به ترتيب 19/•، ه9/• و ه9/• كزارش شد كه مقادير قابل

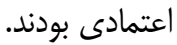
در اين بزوهش بعد از انجام همـاهنكى هـاى لازم بـا مســـولين دانشكده و دانشخاه علوم بزشكى شهيد بهشتى و بيمارستانهاى مورد يزوهش، يزوهشكَ در بيمارستانها حاضر شده و اطلاعات لازم در مورد يزوهش در اختيار شركت كنندًان قـرار كَرفت و در مورد محرمانه ماندن اطلاعات و اختيـارى بـودن شـركت در مطالعه بــه بيمـاران توضـيح داده شـد، سـيس ابـزار گـــدآورى اطلاعات در اختيـار شـركت كنــدكانيزوهش قـرار داده شــه و توسط يُوهشخر با سؤال از سالمندان تكميل گرديد. براى انجام ارزيابىهاى تنسنجى و نمايه توده بدنى (BMI)، وزن بيمار بـاـ حداقل يوشش و بدون كفـش و بــا يـــ تـرازوى ديجيتـال بـاــا

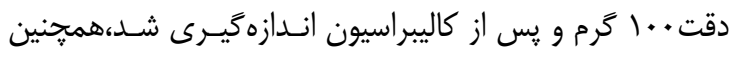
قد، دور باسن، دور كمر و دور بازو با نوار مترى غيرقابل ارتجـاع با دقت / • سانتى متر اندازه گيرى شده و جهت بـرآورد BMI

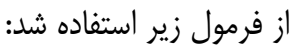




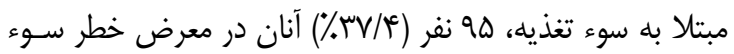

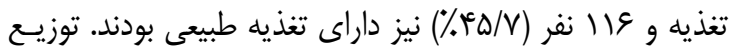

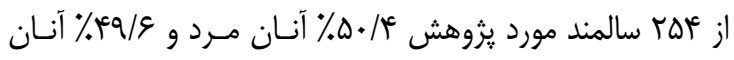
واحدهاى مورد يزوهش بـر حسب مشخصـات دموكرافيـى در

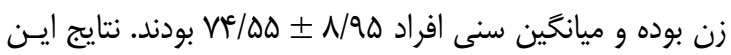
جدول شماره ا نشان داده شده است. مطالعه نشان مىدهد كه سع نفر (9/9 \$\%) از افراد مورد بررسى

جدول ا: توزيع واحدهاى مورد يزوهش بر حسب مشخصات دموكرافيك

\begin{tabular}{|c|c|}
\hline تعداد (درصد) & مشخصات دموكر افيك \\
\hline $\operatorname{ITN}(\% \cdot \Delta \cdot / F)$ & جنس \\
\hline $1 \pi \varepsilon(\%+q / \varepsilon)$ & زن \\
\hline $1 \wedge q\left(\% V^{c} / \kappa^{c}\right)$ & محل زندگى \\
\hline$\varepsilon \Delta(\% \Gamma \Delta / \&)$ & روستا \\
\hline$f(\% / /)$ & وضعيت تأهل \\
\hline $\operatorname{Igr}(\varepsilon \pi / \Lambda)$ & متأهل \\
\hline$r(\% / r)$ & مطلقه \\
\hline$\Lambda \&(\% \mu / 1)$ & بيوه \\
\hline$V \Delta(\% / \% q / \Delta)$ & ميزان تحصيلات بيسواد \\
\hline $9 \cdot(\% \pi / 9)$ & ابتدايى \\
\hline$r q(\%) \omega / \uparrow)$ & راهنمايى \\
\hline$\Lambda \cdot(\% / M / \Delta)$ & ديبلم و بالاتر \\
\hline$V T(\%$ VN/r) & بيكار \\
\hline$\|(\% \Delta / 1)$ & آزاد \\
\hline $\operatorname{Dr}(\% \cdot \% \cdot / \Delta)$ & كارمند \\
\hline$\uparrow \wedge(\% \backslash \wedge / q)$ & خانه دار \\
\hline $99(\% r V / r)$ & ساير مشاغل \\
\hline
\end{tabular}

جدول r: مقايسه متغيرهاى بييوسته بر حسب شاخص سوء تغذيه (بر اساس آناليز واريانس)

\begin{tabular}{|c|c|c|c|c|}
\hline P-value & $\begin{array}{c}\text { (انخراف ميانخين نرمال } \\
\text { (انغيار) }\end{array}$ & در معرض سوء تغذيه & 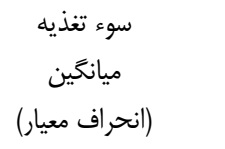 & نرمال \\
\hline$<\cdot / . .1$ & $v \cdot 1 . q(\varepsilon / r q)$ & $V T / \Lambda \Delta(\Lambda / \Delta))$ & $\Lambda \Gamma / \Lambda)(\Lambda / \cdot \Delta)$ & سن \\
\hline$<\cdot / . \cdot 1$ & $V \cdot / \cdot V(1 / r))$ & $q \pi / \Delta \cdot(1 / \kappa r)$ & $\Delta \Delta / \wedge q(1 / \Gamma \cdot)$ & وزن \\
\hline$<. / . .1$ & I & $|\varepsilon|(\varepsilon / \& \Delta)$ & $1 \varepsilon \cdot(V / \Delta Y)$ & قد \\
\hline$<\cdot / . .1$ & 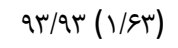 & $\Lambda \mu / \Lambda \Lambda(1 / q \cdot)$ & $V T / G T(T / F \Lambda)$ & دور كمر \\
\hline$<\cdot / .+1$ & $1 \cdot 1 / 97(1 / 99)$ & $q \cdot / \cdot r(1 / V))$ & $V \Delta / r \cdot(1 / 9 \cdot)$ & دور باسن \\
\hline \multirow[t]{2}{*}{$<\cdot / \cdot \cdot 1$} & (س) & $r \Delta / r \mu(\tau / r) r)$ & $r T / \Delta)(\tau / Q)$. & دور ساق پا \\
\hline & & & ميانكين رتبهها & متغير غير نرمال \\
\hline$<\cdot / . \cdot 1$ & $V r / 99$ & $\pi \cdot / \Lambda$. & $10 \% / 19$ & دوربازو \\
\hline
\end{tabular}


جدول س: رابطه بين وضعيت تغذيه و متغيرهاى كيفى

\begin{tabular}{|c|c|c|c|c|}
\hline Pvalue & تغذيه نرمال(7 (I) تعداد(درصد) & معرض سوء تغذيه (90) & 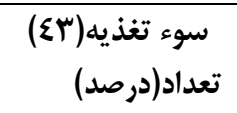 & متغير \\
\hline & & & & جنسيت \\
\hline \multirow[t]{3}{*}{$.1 . \mu f$} & $\xi \wedge(\Delta \Lambda / \xi)$ & 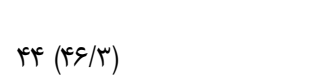 & $19(T V / T)$ & مرد \\
\hline & 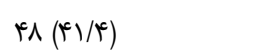 & D) $(\Delta r / V)$ & $r V(g r / \Lambda)$ & زن \\
\hline & & & & وضعيت تأهل \\
\hline \multirow[t]{5}{*}{$<\cdot / \cdot \cdot \mid$} & $\mathcal{F}(\Psi / \mathcal{F})$ & $\cdot(\cdot)$ & $\cdot(\cdot)$ & مجرد \\
\hline & $9 F(\Lambda))$ & $\Delta f(\Delta \xi / \Lambda)$ & $10(r r / q)$ & متأهل \\
\hline & $\operatorname{IV}(I F / V)$ & F) $(F T / T)$ & $r \varepsilon(\varepsilon \cdot / \Delta)$ & بيوه \\
\hline & $1(\cdot / 9)$ & $\cdot(\cdot)$ & $r(\boldsymbol{F} / V)$ & مطلقه \\
\hline & & & & BMI \\
\hline \multirow[t]{5}{*}{$<\cdot / \cdot+1$} & $\cdot(\cdot)$ & $\varepsilon(\xi / \mu)$ & $\Pi(\mu / T)$ & كمبود وزن \\
\hline & $\varepsilon r(\Delta r / T)$ & $\Delta \xi(\Delta \Lambda / Q)$ & $r \Delta(\Delta N / I)$ & وزن نرمال \\
\hline & 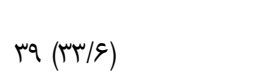 & ra $(r \varepsilon / \Gamma)$ & $r(r / V)$ & اضافه وزن \\
\hline & $1 F(\% \mid r / 1)$ & $\Lambda\left(\Lambda / \varphi^{c}\right)$ & $r \% \vee)$ & جاقى مفرط \\
\hline & & & & ابتلا به بيمارى مزمن \\
\hline \multirow[t]{3}{*}{$<+1 \cdot+1$} & $g \vee(\% \Delta V / \Lambda)$ & $V \cdot\left(\% V^{\mu} / V\right)$ & $\Gamma(\%, M / F)$ & دارد \\
\hline & rq $(\% \leftarrow r / T)$ & ro $(\% / r \& / T)$ & $\Delta(\%) / /)$ & 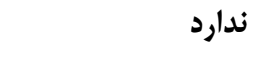 \\
\hline & & & & مصرف بيش از س دارو \\
\hline \multirow[t]{2}{*}{$<\cdot / \cdot+1$} & $r q(\% r \Delta)$ & $\Delta \Lambda(\% / . / / 1)$ & $r \wedge(\% \& \Delta / 1)$ & دارد \\
\hline & $\wedge \vee(\% \vee \Delta)$ & $r V(\%$ (\%/q) & $19(\%$ mF/q) & ندارد \\
\hline
\end{tabular}


و كاهش عملكرد شناختى اسـت [^]. يافتـهـــاى ايـن مطالعـه

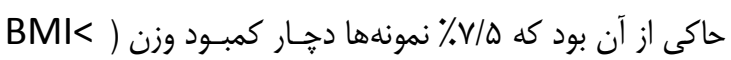

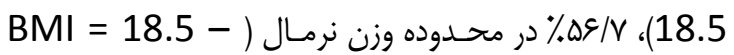

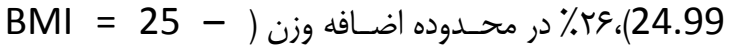
29.99) و 9/1\% نمونه ها دجار خاقى بـا BMI>30 بودنـــ و

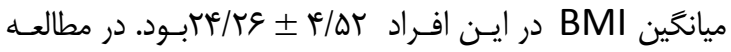
قربانى و همكاران (• وسا) در قزوين [سו]، ميانگين سنى افـراد

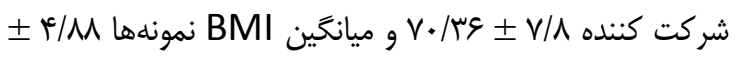
T ب/M/M بود. در مطالعه حاضر بين وضعيت تغذيه و شاخص تـوده بدنى ارتباط معنى دارى وجود داشت (P value = 0.001$)$

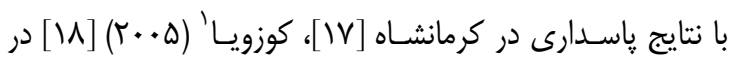
زاين و دنينى و همكاران (سا +r) در ايتاليا [19] همخوانى دارد. يافتهها نشان داد كه افزايش سن با بروز سوء تغذيه ارتبـاط دارد كه با نتايج مطالعات دنينى (س1 +r) [19] ، سودرهام و همكاران’r (r)

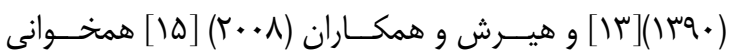

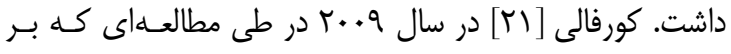
روى بيماران بسترى در بيمارستانهاى تركيه انجام داد گَزارش كرد كه هץ\% از بيماران •و سال به بالا سوء تغذيه داشتند. لازم به ذكر است نتايج اين مطالعه با نتايج معصومى (اوسו) [Tr] و

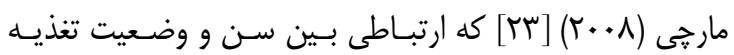
وجود نداشت، متفاوت بود. در اين يثوهش عامل جنسيت هم بـا وضعيت تغذيه ارتباط داشت به طورى كه نتـايج نشـان داد كـــ زنان نسبت به مردان بيشتر در معرض سوء تغذيه و خطـر ابـتلا به آن هستند كه اين نتايج با مطالعه معصومى (اوسا)، مـارجى

1-Kuzuya

2-Soderhamn, et al
يزوهش حاضر به منظور تعيين وضعيت تغذيه و عوامل مرتبط با آن، بر روى FDF سالمند بسترى در بخـش مراقبـتهـاى ويـرثه قلبى صورت گرفت. نتايج اين مطالعه نشان مىدهد كه سع نفـر

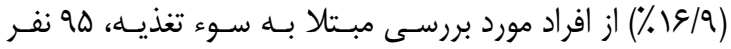

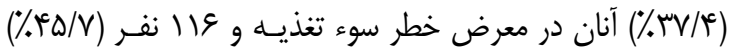

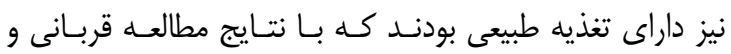
همكاران كه در سالمندان بسترى در بخشهاى داخلى و جراحى

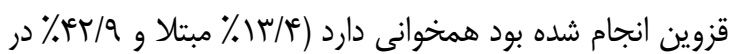
معرض سوء تغذيه) [سا]]. اين ميزان نسبت به نتايج ارائه شده در بيماران سالمند در مصـر ( \\٪ مبـتلا و \&هـ\% در معـرض سـوء تغذيه) [FI] تغذيه) [1ه] كمى تفاوت دارد كه مىتواند به علت تفـاوتهـاى فرهنگى و نوع مواد غذايى مورد استفاده در كشـورهاى مختلـف

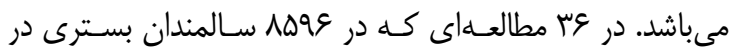

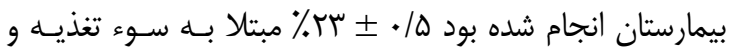

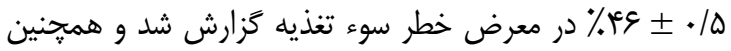
در مطالعات ديخرى كه بر روى • هر هزار سـالمند بـا اسـتفاده از يرسشنامه ارزيابى مختصر تغذيهاى (MNA) انجام شده، شـيوع سـوء تغذيـه در سـالمندان سـالم جامعـه \٪، ع٪ در سـالمندان مراجعه كننده به مراكز سـريايی، هـ٪ در افـراد سـاكن در مراكـز

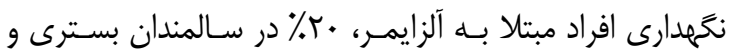
Vr\% در سراى سـالمندان خـزارش شـــه اسـت [ع|]. وضـعيت تغذيهاى بيماران بسترى ارتباط مستقيم با وضـعيت بـالينى آنهـا دارد. علل سوء تغذيه در سالمندان بسترى كاهش اشتها، كاهش مصرف ميـان وعـدههـا بخصـوص در مـردان، تغييـر وضـعيت سلامتى، مشكلات گوارشى، مصرف داروهاى متعدد، افسردگى 
ساكنين خانه سالمندان و آنانى كه بـا دوسـتان و آشــايان خـود زندگى مى كردند، بيشتر بوده و سالمندانى كه با همسر و فرزندان زندگى مى كردند (D//V) وضعيت تغذيهاى بهترى داشتند كه با نتايج مطالعه على آبادى (هیرץ) [• • مطابقت داشت. مطالعات نشان داده انزواى اجتماعى با مصرف ناكـافى كـالرى در ارتبـاط

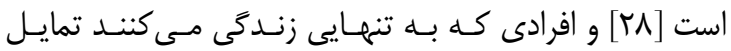
كمترى به مصرف يروتئين، ميوه و سبزيجات داشته و وعدههاى غذايى كمترى نسبت به ديكران مصرف مى كنند [9"]. نتايج وضعيت تغذيه بر حسب شغل نشان داد كـه امكـان سـوء تغذيه در افرادى كه بيكار بودند بيشتر بوده و بين وضعيت تتذيه و شغل ارتباط معنادار وجود داشته و اين متغير بر وضعيت تغذيسه تأثيركذار است، كه اين يافته با مطالعه على آبادى (هیזו) [•l] مطابقـت دارد. همجنـــين وضـعيت تغذيـهاى ســالمندان مـورد يُزوهش با منبع درآمدى آنان ارتباط معنادار داشـته بطـورى كـهـ درصد سوء تغذيه در سالمندانى كه تحت يوشش كميته امـداد و يا بهزيستى بودند بــيش از سـاير سـالمندان بـا منـابع درآمـدى مختلف بود كه اين نتايج با عنايـت بـهـ اينكـهـ حقـوق دريـافتى سالمندان از اين مراكز، بسيار نإِيز اسـت و پِاسـخَّوى تـأمين نيازهاى سالمندان اعم از دارو و غذا كافى نيسـت، دور از انتظـار نمىباشد. در راستاى نتايج مطالعه حاضر، ديخـر مطالعـات نيـز

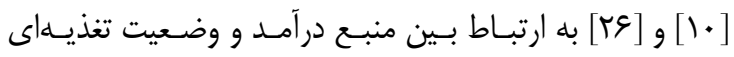
سالمندان اشاره كردهاند. در اين مطالعه وضـعيت تأهـل، عامـل ديخرى است كه با وضعيت تغذيه سالمندان در ارتبـاط بـود، بـهـ طـورى كـه سـالمندان متأهـل نسـبت بـهـ سـايرين در شـرايط مساعدتر تغذيهاى بوده و اكثريت افـرادى كـه نمـره پـايينى در MNA داشتند، بيـوه بودنـــــ ايـن نتـايج بــا مطالـهـ معصـومى

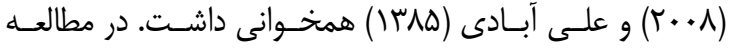

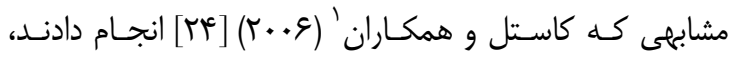

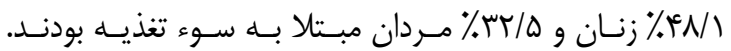

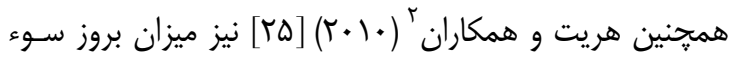
تغذيه را در زنان \&/^٪، در مردان \&/ه٪ و در كـل افـراد جامعـهـ حدود / / ك/رارش كرده است كه به نظر مىرسـد علـت سـوء تغذيـهـ در زنـان عليـرغم BMI بـالاتر در آنـان تفــاوتهــاى بيولوزيكى و عادات غذايى در زنان مىباشد. شايان ذكر است در

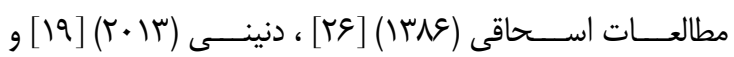

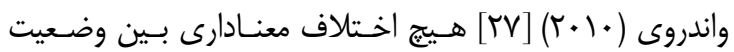
تغذيه زن و مرد وجود نداشت. در اين مطالعه وضعيت تتذيـاى با مكان زندگى (شهر يا روستا) ارتباط نداشت كه با نتايج على أبـادى (همسا) [• [1] همخـوانى نداشـت بـهـ طـورى كـه در آن مطالعه كه در سالمندان آزاد استان خراسان رضوى انجـام شـده بود افراد روستايى نسبت به ساكنين شهر بيشتر دهار سوء تغذيه

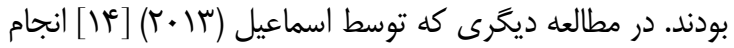
شده بود 9/9٪\% افراد در معرض سوء تغذيه روستايى بودنـــ در مطالعات متعددى [• [1]، [بr] و [بץ]، تحصيلات بـه طـور غيـر مستقيم با وضعيت تغذيـهاى در ارتبـاط بـوده اسـت و در ايـن تحقيق نيز وضعيت تغذيـهاى بـا ميـزان تحصـيلات سـالمندان ارتباط داشت، كه شايد تحصيلات بالاتر منجر به درآمد بيشتر و شيوه زندگى بهتر شده و در نتيجه باعـث بهتـر شــن وضـيت تغذيهاى مى گردد. قابل ذكر است كه دنينى (rا •r) [19] هـيج ارتباط معنادارى بين سطح سواد و وضعيت تغذيه سالمندان بيـدا نكرده و نتايج وى مغاير با اين مطالعه بود. در اين مطالعه درصد شيوع سوء تغذيه و در معرض خطر سوء تغذيه در سالمندان تنها،

1-Castel, et al

2-Herith, et al 
افراد مبتلا به سوء تغذيه مبتلا به انواع بيمارىهاى مزمن بودند

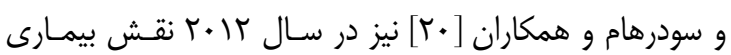
مزمن در بروز سوء تغذيه را گَارش كرد. كه دليـل ايـن ارتبـاط اين است كه با افزايش سن، ميزان سوء تغذيـهـ و بيمـارىهـاى مزمن هر دو شايع شده، و سوء تغذيه منجر به بيمارى و بيمارى

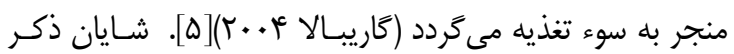

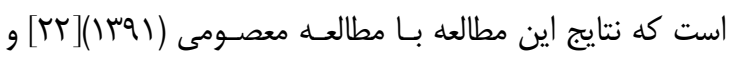

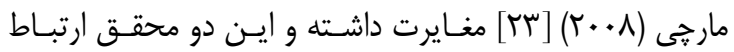
معنى دارى را بين ابتلا به بيمارى مزمن و شيوع سوء تغذيه و يا خطر آن گزارش نكردند. مطالعات متعـددى وجـود دارد كـهـ بــه نقش يلى فارمسى ' (مصرف داروهاى متعدد) بر وضـعيت تغذيـه سالمندان اشاره مى نمايد كـهـ علـت آن ايـن اســت كـه درمـان دارويى منجر به كاهش اشتها، تهوع، اسهال، تغييرات وزن، تغيير در حس جشايى و كاهش توليد بزاق شده و تمامى اين عـوارض باعث افزايش شيوع سوء تغذيه در سالمندان مى توجه به آنجه گَفته شد برآن شديم تا در اين مطالعه به بررسى رابطه بين مصرف بيش از سه دارو در روز و بروز سوء تغذيسه در سالمندان بيردازيه، كه نتايج حاكى از آن بود كه مصرف بيش از سه دارو در روز باعث ابتلا به سوء تغذيه و يا افـزايش خطـر آن مى نداشت. همجنين در اين مطالعه ارتباط معنى دارى بين وضعيت تغذيه و مصرف مكملهاى غذايى به دست نيامد كه بـا مطالعـه على آبادى (هیرسا) [• [1] مغايرت داشت به طورى كه در مطالعه مذكور، درصد سوء تغذيه در مصرف كنندگان مكملهاى غذايى

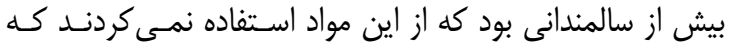
استدلال محقق بر اين اساس بوده كه اين مسأله مىتواند به دو

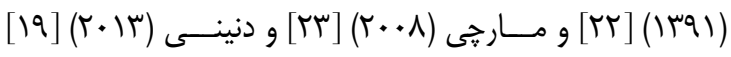
همخوانى نداشت.

نتـايج يـرُوهش حاضـر مبـين ارتبـاط بـين وضـعيت تغذيـهاى سالمندان با تمامى متغيرهاى فوق الـذكر مـىباشــــ و همجنـين ميانگَين وزن، قد، دور كمر، دور باسن و دور بازو در گروهى كـه وضعيت تغذيه نرمال دارند بيشتر و در گروه سـوء تغذيـهـ مقـدار كمترى دارند و مىتوان نتيجه گرفت كه هر كدام ازين شاخصها به طور معنى دارى مىتواند به عنوان ملاكى براى تعيين سوء

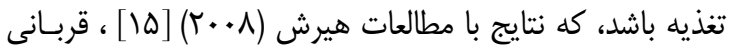

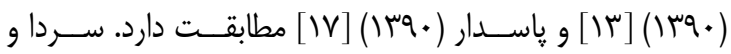

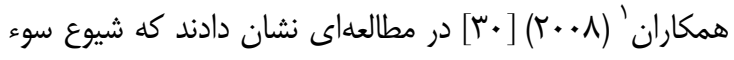
تغذيه بـا BMI يـايين، وزن كـم و نـاتوانى در حركت ارتبـاط

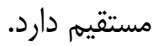
نتايج حاصل حاكى از وجود ارتباط معنى دار بين وضعيت تغذيـهاى سالمندان و عوامل مربوط به وضعيت سلامتى مانند دفعـات بسترى در بيمارستان، وجود بيمارى زمينهاى و مصرف بـيش از سه دارو در روز بوده و رابطه معنى دارى بين وضعيت تغذيه بـاــا مصرف مكملهاى غذايى به دست نيامد. به طورى كـه /ههـ٪\% سالمندان مبتلا به سوء تغذيه سابقه بسترى در بيمارستان را بين ا تا ץ بار در طى سه ماه كذشـته ذكـر كـرده بودنــد. همجنـين يافتهها نشان داد كه بين وضعيت تغذيه و ابتلا به بيمـارىهـاى مزمن ارتباط معنادار وجود داشته و افرادى كه بــه بيمـارىهـاى مزمن مبتلا هستند بيشتر در معرض سوء تغذيـهـ و ابـتلا بــه آن مىباشند و اين موضوع مى تواند به عنـوان يـك عامـل مـؤثر و حمايت كننده از سلامت باشد يا بـه عبـارتى تغذيـه نرمـال بـر

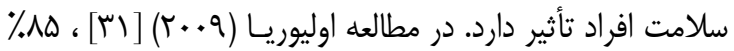

1-Cereda, et al 
بيماريهاى مزمن وضعيت تغذيهاى را تحت الشعاع قرار مى دهد،

لذا ضرورى است جهت شناسايى افراد در معرض خطر، اصـلاح

تغذيه و ييشكيرى از خطرات مرتبط با آن تدابير مناسـب اتخـاذ

$$
\text { Sرد }
$$

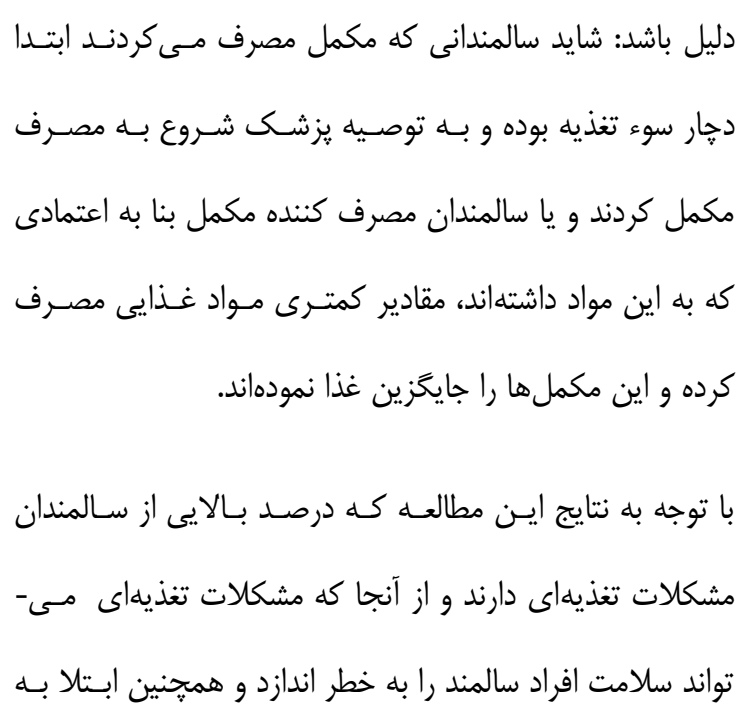

\section{- References}

1.Darvishpoor Kakhki, A., et al., Tools for measurement of health status and quality of life of elderly people. Research in Medicine, 2010. 33(3): p. -162-173.

2. $\mathrm{WH}, \mathrm{O}$. Launches new initiative to address the health needs of rapidly aging population. 2006] cited 2006; Available from: http:/www.who.int

3. Talebi, n., mirzazadei.A, and A.A. haghdoost, Epidemiological Characteristics and Determinants of Ischemic Heart Disease in Iran. PAYESH, 2009. 8(2): p. -163-170.

4. Gariballa, S., Nutrition and older people: special considerations relating to nutrition and ageing. Clinical medicine, 2004. 4(5): p. -411-414.

5. Wells, J.L. and A.C. Dumbrell, Nutrition and aging: assessment and treatment of compromised nutritional status in frail elderly patients. Clinical interventions in aging, 2006. 1(1): p. 67.

6. Solemdal, K., et al., The impact of oral health on taste ability in acutely hospitalized elderly. PloS one, 2012. 7(5): p. e36557.

7. Amaral, T.F., et al., Undernutrition and associated factors among hospitalized patients. Clinical nutrition, 2010. 29(5): p. -580-585.

8. Feldblum, I., et al., Nutritional risk and health care use before and after an acute hospitalization among the elderly. Nutrition, 2009. 25(4): p. -415-420.

9. Guigoz, Y., S. Lauque, and B.J .Vellas, Identifying the elderly at risk for malnutrition. Clinics in geriatric medicine, 2002. 18(4): p. -737-757. 
10. Aliabadi, et al., Prevalence of malnutrition and factors related to it in the elderly subjects in Khorasan Razavi province. Iranian Journal of Nutrition Sciences \& Food Technology, 2007. 3: p. -245-256.

11. Fernández-Ballart, J., Equation to estimate body weight in elderly Mexican women using anthropometric measurements. Nutr Hosp, 2010. 25(4): p. -648-655.

12. Hirani, V. and J. Mindell, A comparison of measured height and demi-span equivalent height in the assessment of body mass index among people aged years and over in England. Age and ageing, 2008. 37(3): p. -311-317.

13. Ghorbani, a., T. Karimzadeh, and Y. Azadmanesh, Nutritional assessment in elderly hospitalized patients in Qazvin Teaching Hospitals in 2011. Iranian Journal of Ageing, 2013. 8(1): p. $-33-40$.

14. Esmayel, E.M., et al., Nutritional and functional assessment of hospitalized elderly: impact of sociodemographic variables .Journal of aging research, 2013.

15. Hirsch, S., et al., Karnofsky performance scale and Mini Nutritional Assessment predict mortality in geriatric patients. Open Longevity Science, 2008. 2: p. -17-22.

16. Guigoz, Y., et al., THE MINI NUTRITIONAL ASSESSMENT (MNA®) REVIEW OF THE LITERATURE-WHAT DOES IT TELL US?/DISCUSSION. The journal of nutrition, health \& aging, 2006. 10(6): p. 466.

17. Pasdar, Y., et al., Nutritional status using multidimensional assessment in Iranian elderly. Journal of Kermanshah University of Medical Sciences (J Kermanshah Univ Med Sci), 2011. 15(3).

18. Kuzuya, M., et al., Evaluation of mini-nutritional assessment for Japanese frail elderly. Nutrition, 2005. 21(4): p. -498-503.

19. Donini, L.M., et al., Nutritional care in a nursing home in Italy. PloS one, 2013. 8(2): p. e55804.

20. Söderhamn, U, et al., Nutritional screening of older home-dwelling Norwegians: $a$ comparison between two instruments. 2012.

21. Korfal1, G., et al., Nutritional risk of hospitalized patients in Turkey. Clinical nutrition, 2009. 28(5): p. 533-537.

22. Masomy, N., et al., Nutritional Status Assessment and Related Factors in the Retired Senile. Journal of Guilan University of Medical Sciences, 2012. 21(84): p. 65-70

23. De Marchi, R.J., et al., Association between oral health status and nutritional status in south Brazilian independent-living older people. Nutrition, 2008. 24(6): p. -546-553. 
24. Castel, H., D. Shahar, and I. Harman-Boehm, Gender differences in factors associated with nutritional status of older medical patients. Journal of the American College of Nutrition, 2006. 25(2): p. -128-134.

25. Haritha, S., et al., The magnitude of malnutrition among hospitalized elderly patients in university Malaya medical centre. Health Environ J, 2010. 1 :p. -64-72.

26. Eshaghi, R., et al., Elderly nutritional status in Isfahan. Iranian Journal of Ageing, 2007. 2(3): p. 340-345

27. Vanderwee, K., et al., Malnutrition and associated factors in elderly hospital patients: a Belgian cross-sectional, multi-centre study. Clinical nutrition, 2010. 29(4): p. -469-476.

28. Ferry, M., et al., The SOLINUT study: analysis of the interaction between nutrition and loneliness in persons aged over 70 years. AGE AND NUTRITION, 2005. 16(2): p. 60.

29. Ramic, E., et al., The effect of loneliness on malnutrition in elderly population. Medical Archives, 2011. 65(2): p. 92.

30. Cereda, E., L. Valzolgher, and C. Pedrolli, Mini nutritional assessment is a good predictor of functional status in institutionalised elderly at risk of malnutrition. Clinical nutrition, 2008. 27(5): p. -700-705.

31. Oliveira, M.R., K.C. Fogaça, and V.A. Leandro-Merhi, Nutritional status and functional capacity of hospitalized elderly. Nutrition Journal, 2009. 8(1): p. 1.

32. Jyrkkä, J., et al., Polypharmacy and nutritional status in elderly people. Current Opinion in Clinical Nutrition \& Metabolic Care, 2012. 15(1): p1-6. 